\title{
CAMINHOS PRECIOSOS NA EDUCAÇÃO EM QUÍMICA: VISITAS ESCOLARES AO MUSEU DA GEODIVERSIDADE COMO RECURSO FACILITADOR DA APRENDIZAGEM
}

Karine Pires Moreira Guilherme Cordeiro da Graça da Oliveira

\section{Introdução}

Um dos principais objetivos do ensino de Química é propiciar ao estudante interagir melhor com o mundo; devem-se formar cidadãos que, além de interpretar o mundo onde estão inseridos, sejam capazes de transformar este mundo para melhor (CHASSOT, 1993). No entanto, a realidade do ensino tem sido atividades padronizadas sem inserção em contextos reais, colocando o estudante em atitude de passividade diante do aprendizado, em vez de proporcionar a formação de cidadãos críticos (OLIVEIRA e MARCONSIN, 2014). Visitas escolares a locais tais como museus, jardins botânicos, trilhas ecológicas, zoológicos etc - conhecidos como espaços não formais de educação - podem contribuir para tornar o ensino de Química menos asséptico, ou seja, torná-lo mais vinculado à realidade dos educandos. 
Palmieri e Silva (2017) observaram que os museus possuem potencial pedagógico como complemento da educação formal. Para as autoras, esses locais auxiliam na formação cidadã crítica onde as atividades podem iniciar ou complementar a aprendizagem de conceitos químicos. A experiência museal torna os indivíduos protagonistas de suas ações, promove uma sensibilização que pode acarretar no aumento do interesse pela Química após a realização de atividades nesses espaços. Além disso, a experiência museal ajuda a desmistificar o conceito presente no senso comum de que a Química é algo prejudicial. Por fim, as autoras ressaltaram a necessidade de implementação da Química nos museus de ciência e do aumento de pesquisas nessa temática.

No entanto, Oliveira e Marconsin (2014), ao discorrerem sobre a realidade de muitas escolas no Brasil, afirmam que muitas vezes as visitas escolares acabam assumindo um perfil de "passeio", sem qualquer preocupação com os conteúdos apresentados, o que caracteriza uma subutilização de um espaço rico em potencialidades educativas. Para os autores, as visitas devem ser planejadas de forma adequada, considerando a literatura específica da área. Desse modo, faz-se importante inserir, na formação inicial de professores, conteúdos e ações relacionados a esse tipo de atividade, bem como realizar mais pesquisas nessa área. 
Visando contribuir para a discussão sobre a utilização dos espaços não formais para o ensino e aprendizagem de química, esse capítulo discorre sobre as possibilidades de elaboração de um trabalho de apropriação do acervo do Museu da Geodiversidade (MGeo) - localizado no Instituto de Geociências na UFRJ - para fins de se trabalhar conteúdos de química de uma forma capaz de despertar a motivação para a continuidade dos estudos entre os alunos. O MGeo busca uma integração das geociências e do entendimento do porquê, onde e como ocorrem os desastres naturais, tais como terremotos, furacões, vulcões, mudanças climáticas, retratando a história geológica da Terra. O museu abriga a terceira maior coleção de fósseis no país, catalogada pelo sistema Paleo do Serviço Geológico do Brasil, de acervos disponíveis na internet. Compreende ainda um acervo de aproximadamente 20.000 minerais, rochas, solos e além de fotografias, instrumentos de uso em geociências, mapas, documentos e livros raros. Deste acervo fazem parte materiais de extrema raridade como o meteorito Uruaçu, holótipos de fósseis brasileiros (tipos de referência científica), minerais e rochas raras (Brasil, 2012). O trabalho no museu não se encerra com a organização e montagem das exposições. $\mathrm{O}$ acervo é permanentemente atualizado com novas descobertas trazidas pelo corpo docente e discente do Instituto de Geociências. Para que mantenha um caráter dinâmico, o espaço conta atualmente com o trabalho de duas museólogas, um historiador, um pedagogo e sete bolsistas. 
Não se pretende, contudo, produzir um material que padronize as atividades docentes/discentes mas sim, através da experiência adquirida, demostrar as diversas possibilidade que o acervo oferece em termos de trabalho dos conteúdos de química.

\section{A educação para além dos muros escolares}

Os denominados passeios ${ }^{1}$ fazem parte, há muito tempo, do cotidiano de escolas. No entanto, muitas vezes, eles ocorrem sem qualquer compromisso pedagógico. Os estudantes são deslocados das escolas sem um planejamento adequado; os professores que levam os estudantes, por conta de problemas de horários, nem sempre são os que organizaram a atividade, e às vezes, não entendem a importância dessa experiência.

Existem, também, fatores que desmotivam os professores a sair com os alunos, a saber: a falta de apoio da direção da escola, a falta de tempo e o cansaço do professor que precisa trabalhar em várias escolas para ter uma renda adequada, a logística que envolve a atividade autorização de responsáveis, transporte, lanche -, e até mesmo a violência urbana (OLIVEIRA e MARCONSIN,

\footnotetext{
${ }^{1}$ Embora a expressão "passeio" seja ainda muito utilizada, deveria ser evitada, pois a conotação é de que seria uma atividade sem qualquer compromisso pedagógico.
} 
2014). Com tantos fatores desfavoráveis, o que justificaria a saída dos alunos do ambiente escolar?

Quando se considera os estudantes de escolas públicas periféricas que, muitas vezes, não possuem o hábito de visitar instituições culturais, torna-se essencial o papel da escola. Ao promover essas atividades, a escola atua reduzindo as desigualdades socioculturais, assumindo uma função transformadora na vida de seus estudantes.

Atividades extra ambiente escolar remetem ao trabalho do pedagogo francês Célestin Freinet (18961966) que, preocupado com o desempenho de seus alunos, desenvolveu uma técnica pedagógica denominada aula-passeio (do francês "classe promenade"). Freinet notou que os alunos ficavam mais alegres quando efetuavam saídas ao entorno da escola e que, tal alegria e motivação, se mantinham no retorno à escola. Assim, desenvolveu também outras técnicas tais como texto-livre, imprensa escolar, correspondência interescolar, autoavaliação, livro da vida, fichário de consulta e plano de trabalho. A pedagogia Freinet é estruturada pelos seguintes eixos: livre-expressão, autonomia, trabalho, cooperação e afetividade (AMORIM, CASTRO E SILVA, 2012; MATOS E VITORINO, 2018; FREINET, 1975; ARAUJO E PRAXEDES, 2013; LEGRAND, 2010). 
Mais recentemente, Griffin (1998) desenvolveu o "SMILES" (School-Museum Integrated Learning Experiences in Science), um programa que descreve uma lista de sugestões para o trabalho no ambiente museal, a saber: participação dos estudantes na escolha de locais e temas, grupos pequenos com certa autonomia de trabalho, oportunidade para descanso físico e mental durante a visita, escolha de atividades complementares às atividades desenvolvidas no museu, possibilidade de compartilhamento das experiências vivenciadas através de atividades como seminários, oficinas, workshops etc.

Falk e Storksdieck (2005) investigaram as possibilidades de aprendizagem no ambiente museal através do Modelo de Aprendizagem Contextual (MAC). Nesse modelo, a aprendizagem é definida como um esforço direcionado e contextualizado que permite construir significados na direção de resolução de problemas, sobrevivência ou prosperidade no mundo. Para os autores, a aprendizagem que se desenvolve durantes uma experiência museal é facilitada através do diálogo que se estabelece entre o indivíduo e o meio ao longo do tempo, relacionando experiências passadas e atuais. Esse diálogo direcionado como um processo/produto de interações que ocorrem nos contextos pessoal, sociocultural e físico, cada um agrupando determinados fatores facilitadores da aprendizagem. No contexto pessoal, há os seguintes fatores: motivação e expectativas, experiência e conhecimento prévios, interesses e convicções, escolha e controle; a 
aprendizagem é fortemente influenciada pelos interesses, experiências prévias e convicções do indivíduo (OLIVEIRA E MARCONSIN, 2014). Esses fatores facilitadores, de certa forma, se aproximam das ideias de Chassot (1993), quando este questiona "por que não ensinar a Química partindo da realidade dos alunos, escolhendo (ou deixando os alunos escolherem) temas de seu interesse". O contexto sociocultural possui dois facilitadores: mediação social do grupo e mediação facilitada por outros. Esse contexto está relacionado às diversas possibilidades de interação de um visitante com os demais, bem como a presença de mediadores ou guias, ou qualquer outra atividade artística e/ou educacional elaborada para fins de que a visita se torne a mais agradável e prazerosa possível. O contexto físico contém quatro facilitadores: organização antecipada, orientação do espaço físico, arquitetura e ambiente, exposições e conteúdo das legendas, eventos posteriores e experiências fora do museu. Esse contexto guarda relação com fatores arquitetônicos como a iluminação, aglomeração de pessoas, qualidade e quantidade de informações apresentadas etc. E, ao considerar que a aprendizagem não é um fenômeno instantâneo, mas sim um processo acumulativo de aquisição e consolidação de significados, as experiências que ocorrem após as visitas são igualmente importantes como facilitadoras da aprendizagem, pois reforçam as experiências vivenciadas no museu (OLIVEIRA E MARCONSIN, 2014). 
Algo notório entre os referenciais teóricos apresentados é que, ao planejar as visitas escolares, os professores devem considerar não só a visita em si, mas o momento anterior à visita e o momento pós-visita. Atividades pré-visita podem fazer com que o aluno adquira um conhecimento inicial sobre o local, motivando-se para a visita e atividades pós visita servem como um reforço dos conteúdos trabalhados.

\section{Construindo caminhos preciosos}

Particularmente para o MGeo, muitas são as possibilidade de se abordar temas de química durante uma visita. A seguir, alguns exemplos são apresentados. A Química pode ser encontrada logo no primeiro módulo, denominado "Abertura", composto por um quadro "falante" do escritor Monteiro Lobato, que contém uma gravação dando boas vindas aos visitantes da exposição (Figura 1). Mas o que Monteiro Lobato tem a ver com Química? Esse escritor foi alguém muito engajado com questões relacionadas ao petróleo - tema presente em conteúdos curriculares de Química -, o que se refletia em suas obras (ANDRADE, 2014). 
Figura 1: Quadro retratando Monteiro Lobato, presente na abertura da exposição Memórias da Terra, em cartaz no MGeo/UFRJ.

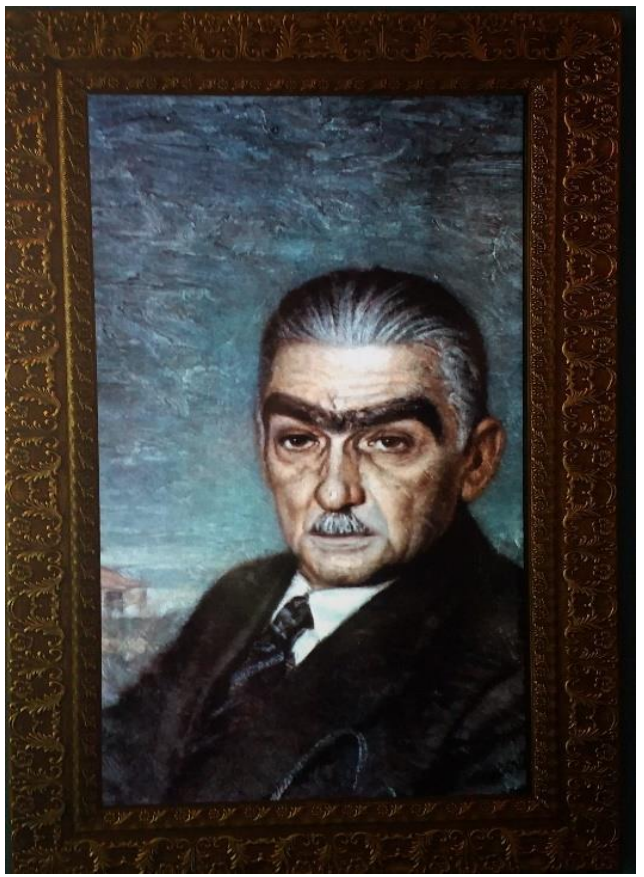

Fonte: os autores.

No módulo "Terra: um planeta em formação" é possível contemplar meteoritos (Figura 2) que fazem parte do rico acervo do museu, bem com um modelo da Terra primitiva, além de um vídeo sobre a formação do planeta Terra e um texto explicativo. Nesse vídeo é apresentada a formação da atmosfera terrestre, sua composição e alterações sofridas com o tempo. Em exposição também encontra-se um fragmento do meteorito de Bendegó. Uma placa explicativa indica os elementos químicos pre- 
sentes e pode ser utilizada para trabalhar conceitos de porcentagem e composição.

Figura 2: Meteoritos em exposição no módulo Terra: um planeta em formação. As placas explicativas contêm informações acerca da composição química desses meteoritos e sobre a importância deles para o estudo da origem da Terra.

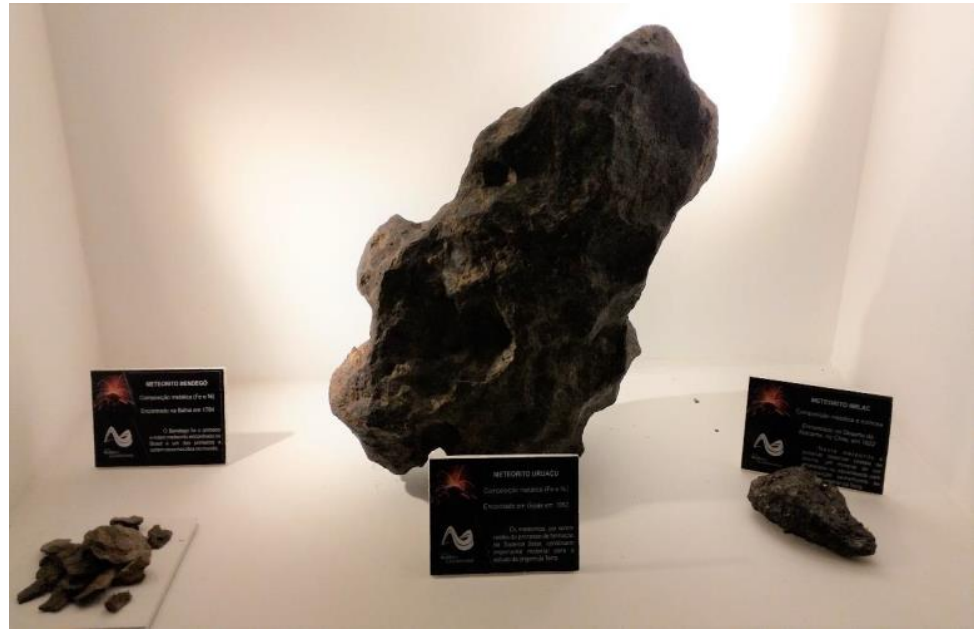

Fonte: os autores.

O módulo "Minerais: frutos da Terra" é a parte da exposição onde a presença de Química é bastante evidente. A Figura 3 exibe parte da coleção em exposição. Aqui o professor pode trabalhar conceitos de elemento químico, substância química, minério, mineral, rocha, estado sólido etc. 
Figura 3: Vitrines com parte da coleção de rochas e minerais presentes na exposição Memórias da Terra.

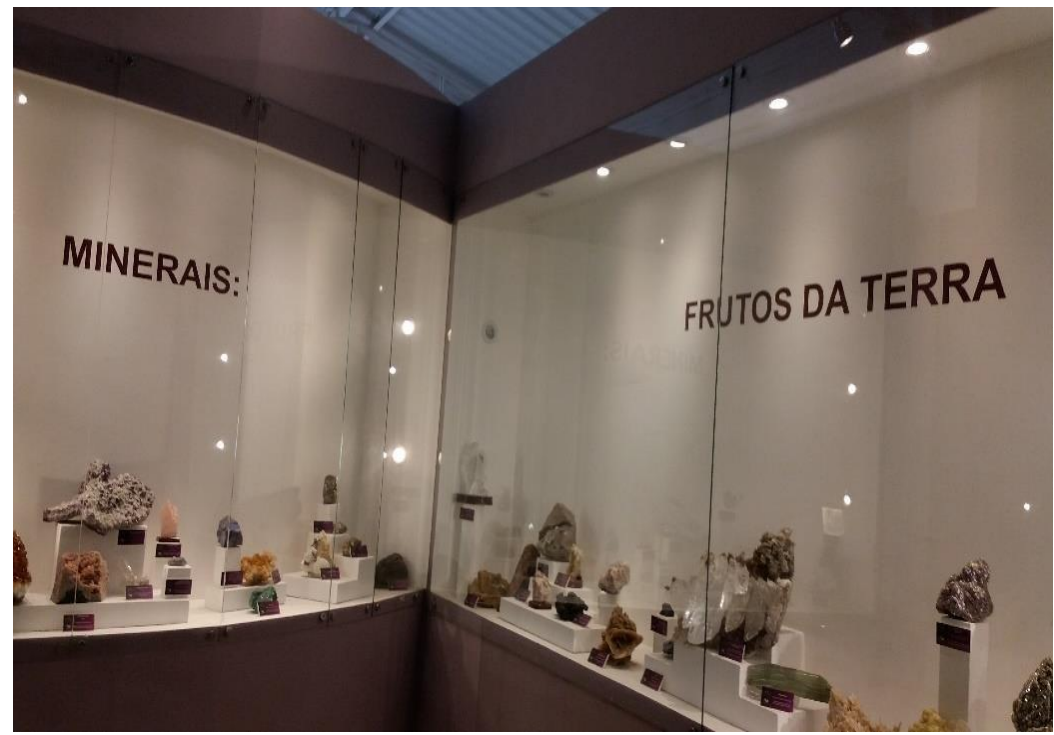

Fonte: os autores.

Ainda sobre o módulo "Minerais: frutos da Terra”, a Figura 4 retrata o texto explicativo apesentado. 
Figura 4: Texto explicativo localizado no módulo Minerais: frutos da Terra, no MGeo

Os minerais são os componentes básicos
das rochas. Apesar da imensa diversidade de
cores, formas e usos, todos se caracterizam
por ser um composto de átomos inorgânicos e
naturais. Além disso, devem estar em estado
sólido e possuir uma composição química
definida (NaCl, por exemplo, que é o sal de
cozinha), com arranjo físico ordenado e
repetitivo. A diferença entre essas
composições e arranjos possibilita a
classificação dos minerais.
Os elementos quimicos presentes nos
minerais, a exemplo do alumínio, do ferro e do
cobre, são utilizados na fabricação da maioria
dos produtos que utilizamos no nosso dia a
dia, tais como metais, tintas e materiais de
construção.
Por esse motivo, os minerais têm imensa
importância para o desenvolvimento
econômico e social humano, além de
constituírem elementos naturais de
indiscutivel beleza, verdadeiros frutos de um
planeta em transformação.

Fonte: os autores.

A presença da Química foi notada, também, em outros setores da exposição: Mares do passado, E a vida conquista os continentes, Tecnógeno: uma realidade, De olho no petróleo (Figura 5). 
Figura 5: Aparato Interativo "De olho no Petróleo". O visitante leva o modelo de produto ao hexágono central, e propriedades desse produto são exibidas na tela

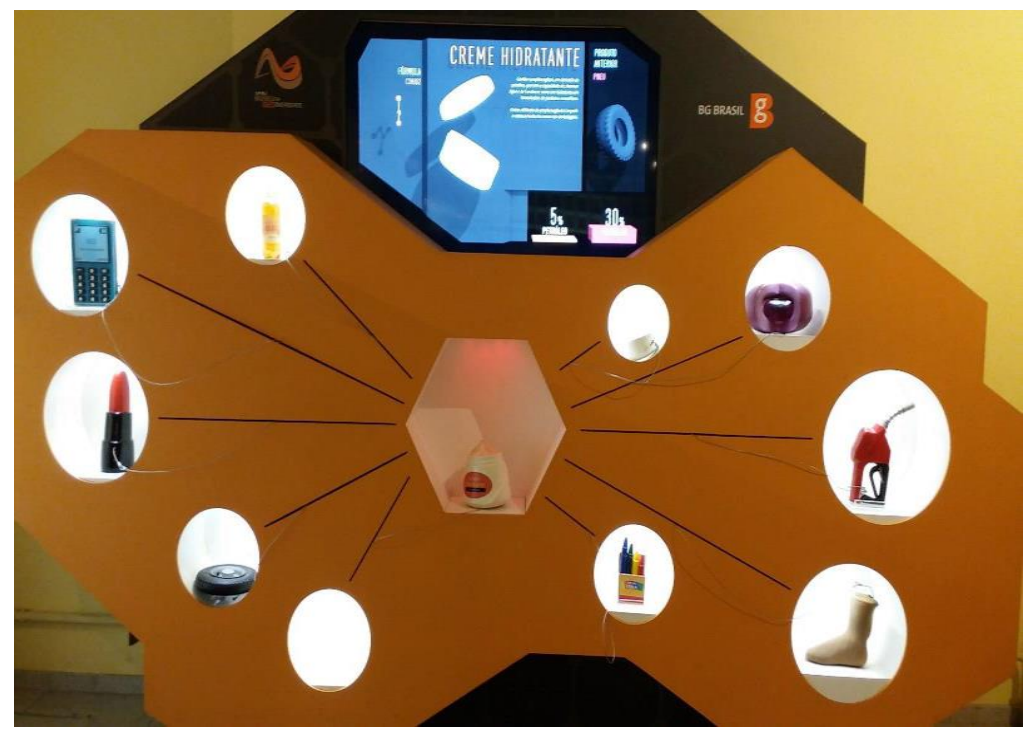

Fonte: os autores.

Importante ressaltar que essa é apenas uma visão dessa exposição; cada educador, ao visitar o museu para elaborar o planejamento, deve realizar sua própria leitura. A partir de um conhecimento prévio do acervo do MGeo, o professor pode elaborar uma sequência didática tendo como referenciais materiais de apoio e sequências didáticas relacionadas ao tema escolhido como, por exemplo, a mineração e seus impactos (NEGRI et al, 2016a; NEGRI et al, 2016b; TARGINO e GIORDAN, 2017a; TARGINO e GIORDAN, 2017b). 


\section{Uma proposta de sequência didática}

1) Momento anterior à visita

Verificar o potencial do museu para a aprendizagem de Química

O professor deve conhecer o museu (regras, acervo, a organização da exposição em si e o agendamento da visita) e pensar em formas de melhor aproveitar a experiência museal. Combinar estratégias com o setor educativo do museu é uma possibilidade.

Sensibilização para o tema

Para fins de exemplificação, foram escolhidas duas artes: a alegoria "O rio que era doce" (Figura 6), do desfile do Grêmio Recreativo Escola de Samba Portela, que ocorreu durante o Carnaval de 2017 e uma charge do cartunista Iotti (Figura 7), publicada no Jornal GaúchaHZ. Nessa sequência didática, as artes são apresentadas como uma sensibilização para o tema. 
Figura 6: Alegoria 4 do desfile da Portela, denominada "O rio de que era doce".

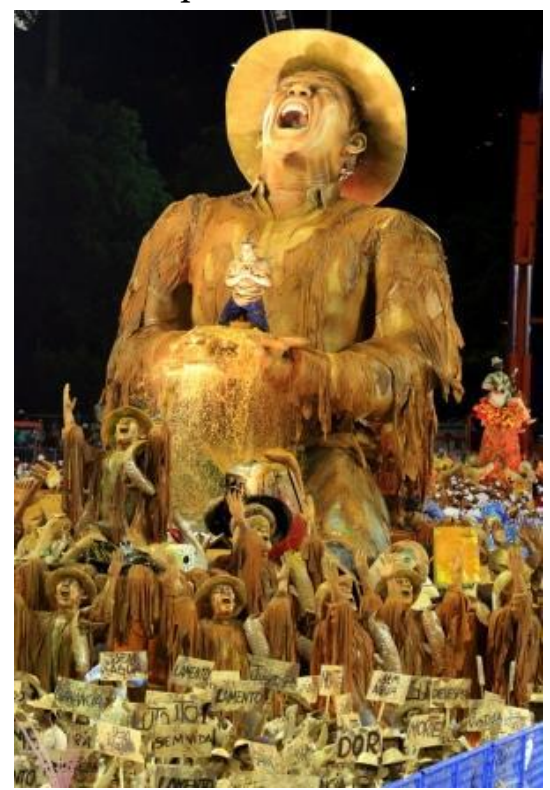

Fonte: Carlos Moraes/Estadão.

A alegoria em questão representa o sofrimento e a luta por justiça da população do município de Mariana (MG) após o impacto do rompimento de uma barragem de rejeitos. Se o educador tiver oportunidade, em vez de usar a imagem, pode até mesmo exibir um vídeo para os educandos, com um trecho editado desse desfile. O desfile das escolas de samba do Rio de Janeiro, embora faça parte da cultura brasileira de uma forma marcante, ainda sofre com preconceitos, em parte pelo elemento principal possuir ancestralidade africana: o samba. A importância do samba, segundo Nogueira e Santos (2018, p. 58): 
Se a escravidão que se abateu sobre o povo negro africano foi abolida há mais de cem anos no Brasil, seus grilhões permanecem presentes no racismo e na desigualdade social. Entendemos que uma das contribuições centrais do samba é o seu alto potencial enquanto transformador e aglutinador social, algo que historicamente favoreceu que comunidades marginalizadas enfrentassem suas condições de exclusão e alcançassem dignidade, reconhecimento e centralidade na cultura nacional. Mais que uma manifestação artística, o legado do samba constrói a interconexão entre as estruturas sociais, laços afetivos, identidades, autoestima e heranças culturais de suas comunidades afrodescendentes de origem.

A escola é o ambiente propício ao debate de variados temas, sem amarras ideológicas. É o lugar de combater preconceitos e busca da transformação social. Nas palavras do necessário e célebre educador Paulo Freire: se a educação sozinha não transforma a sociedade, sem ela tampouco a sociedade muda (FREIRE, 2000, p.31). Os verdadeiros caminhos preciosos envolvem educação, cidadania, solidariedade, respeito aos direitos humanos, justiça social, amor ao próximo, que vão auxiliar os educandos a caminhar na direção de um mundo melhor.

A outra arte escolhida para exemplificar é a charge mostrada na Figura 7 a qual deve suscitar reflexões sobre os motivos que culminaram no crime ambiental de Mariana/MG. 
Figura 7: Charge do cartunista Carlos Henrique Iotti acerca do rompimento de barragens.

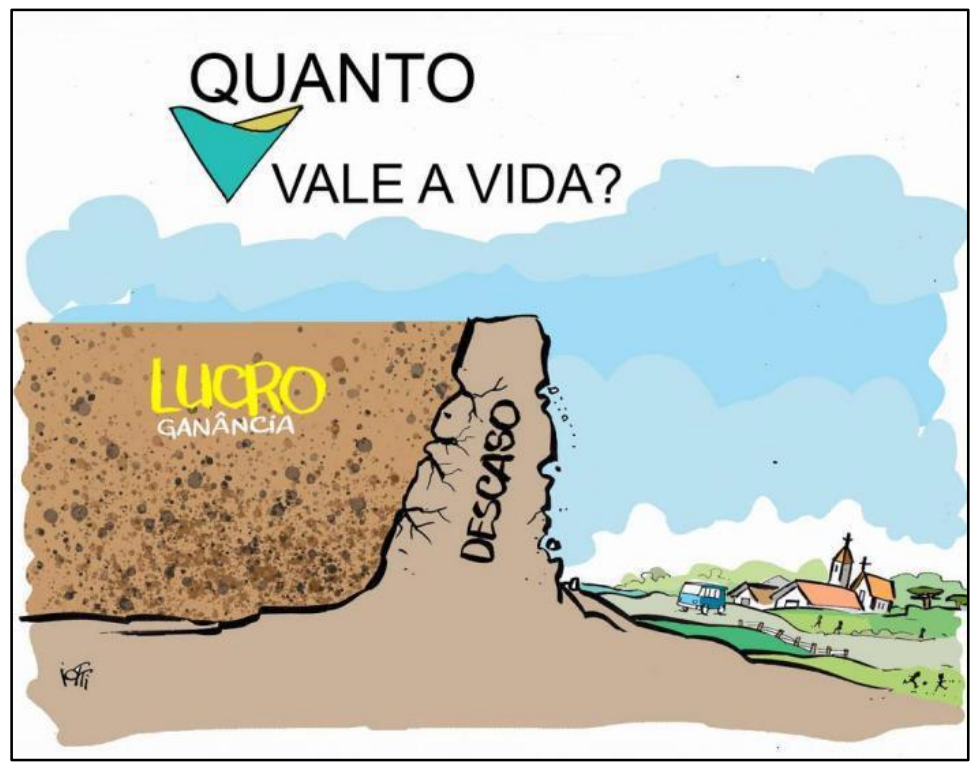

Fonte: Jornal da GaúchaZH.

As obras podem ser exibidas aos educandos, sem qualquer explicação. Eles devem interpretá-las apenas utilizando seus conhecimentos prévios. Após uma pausa para os educandos refletirem sobre as obras, o educador pode perguntar o que eles sentiram ao ver tais imagens, e verificar se eles conseguiram fazer a associação com o crime de Mariana/MG.

Ainda nessa fase de sensibilização, os educandos podem exibir vídeos e disponibilizar outros materiais relativos ao tema. Vídeos sugeridos numa sequência didáti- 
ca elaborada por Targino e Giordan (2017a) se mostram boas opções, bem como o material didático de apoio, também desenvolvido por esses mesmos autores.

\section{Minerais e a Química}

Elementos químicos, Tabela Periódica, substâncias puras e misturas, separação de misturas, substâncias iônicas, solubilidade, número de oxidação, são exemplos de conteúdos de Química que podem ser abordados considerando essa temática. Negri et al (2016b), por exemplo, propuseram uma atividade com o tema "A Química e a Mineração”, na qual abordaram o conceito de minério, discorrendo sobre a economia de produção e exportação de ferro no Brasil, relacionando a conceitos químicos, a saber: substâncias puras, misturas e grau de pureza de uma substância.

Após trabalhar os conteúdos de Química, o professor pode informar aos educandos sobre a visita ao MGeo e disponibilizar a eles o site, para que eles se preparem para a visita. O museu dispõe de uma rica exposição de minerais e minérios bem como de um breve histórico da importância desses materiais para a economia brasileira. 


\section{Visita ao Museu}

É essencial, para um bom trabalho educativo em espaços não formais, que o professor e a equipe de auxílio na mediação realizem visitas prévias ao local escolhido. Essas visitas servem para conhecer com detalhes as regras, o acervo, a disposição dos materiais, textos explicativos, iluminação etc que serão utilizados no momento da visita. No caso do MGeo, a visita se inicia com o acolhimento dos educandos no auditório anexo onde eles são informados sobre as regras do museu, sobre a UFRJ, seus centros, unidades e cursos. Caso a turma seja muito numerosa, ela deve ser dividida. Uma sugestão é de que se tenha, no máximo, 8 alunos para cada mediador. Algumas considerações sobre visitas escolares realizadas ao MGeo podem se encontradas na literatura (OLIVEIRA e MOREIRA, 2018).

Cada aluno recebe orientações das atividades a serem executadas durante a visita. Essa tarefa deve servir apenas para orientar o visitante, fazer com que ele interaja com os colegas, mediadores, buscando, no acervo do museu, as respostas das questões colocadas. As atividades não devem pode ser longas ou muito complexas, para não tornar a visita entediante. O mediador deve procurar instigar, interagir, motivar e tentar captar os interesses dos visitantes. Após a visita, todos devem retornar ao auditório, onde pode ser perguntado aos educandos de que eles mais gostaram e menos gostaram na visita, além de ori- 
entar os educandos a realizarem atividades pós-visita, para serem finalizadas na escola.

Atividades a serem executadas durante a visita

1- Registre, com aparelho celular, partes da exposição que você acha que têm ligação com a Química.

2- Responda o que se pede, considerando a exposição "Memórias da Terra", do Museu da Geodiversidade.

a) Que elementos químicos estão presentes na composição do meteorito do Bendegó? Onde ele foi encontrado e em que ano?

b) O que é minério? Registre, com aparelho celular, o mineral presente na exposição que é usado como minério de ferro. Qual o nome e a composição química desse mineral?

c) Dê exemplos de 3 minerais e seus respectivos usos.

d) O que possibilitou o aparecimento da Formação Ferrífera Bandada?

e) A atmosfera primitiva era formada principalmente pelos gases e

f) A história humana está interligada aos materiais, desde a Idade da Pedra até a Idade do__ que é a Era atual. 
g) Cite 2 produtos que tenham derivados de petróleo em sua composição.

\section{Após a visita}

As atividades, obviamente, vão variar conforme os objetivos do planejamento do educador. Aqui, serão dadas algumas sugestões, dentro da temática considerada no exemplo apresentado.

1- Os alunos deverão escolher pelo menos uma imagem que registraram do museu, explicar a relação dessa imagem com a Química ou com o crime ambiental de Mariana/MG, e produzir uma arte que seja relacionada à imagem. Pode ser um meme, charge, texto, vídeo ou música. Os alunos deverão fazer em casa e levar na aula seguinte à visitação.

2- Discussão das repostas que os alunos deram na atividade realizada no museu.

3- Debate: Na visita ao museu, foi vista a importância dos minerais em nosso cotidiano. Há limites ou vale tudo pelo progresso? Considerar os crimes ambientais de Mariana $e$ Brumadinho com as barragens para o debate. A turma pode ser dividida em duas partes, uma elabora pontos positivos, $e$ a outra parte da turma se concentra nos pontos negativos.

Ao fim da sequência didática, o educando deve compreender não só os conceitos de Química, mas perce- 
ber que os caminhos pelos quais deve trilhar não são o do egoísmo, do preconceito e o da ganância. Caminhos preciosos envolvem respeito, dignidade, solidariedade, educação e cidadania. Sabe-se que não há como estimar quanto vale a vida; o educando deve entender, sobretudo, que o direito à vida é fundamental e o mais precioso que existe.

\section{Considerações finais}

Na maioria dos cursos de formação inicial de professores, a temática "espaços não formais de educação" não é trabalhada de forma sistemática a ponto de sensibilizar o docente em formação sobre a importância de tais espaços para a aprendizagem de conteúdos e formação cultural dos estudantes. Nesse trabalho, procuramos evidenciar o imenso potencial educativo a ser aproveitado em museus e, particularmente, no MGeo. Foi possível sugerir elementos para a construção de uma sequência didática para a aprendizagem de Química, envolvendo uma visita escolar ao museu. Desta forma, apresentamos uma entre diversas possibilidades do trabalho docente que, se elaborado com base nos referenciais teóricos que tratam das especificidades da educação museal e sua interação com a educação formal, certamente ocasionará em resultados gratificantes tanto para os estudantes como para o professor. 


\section{Referências}

AMORIM, G. C. C; CASTRO, A. M. N.; SILVA, M. F. S. Teorias e práticas pedagógicas de Célestin Freinet e Paulo Freire. In: IV Fórum Internacional de Pedagogia - IV FIPED. Anais IV FIPED. Campina Grande, REALIZE Editora, 2012.

ANDRADE, J. M. O Poço do Visconde: conceitos de geologia, política e proatividade para crianças. Intersemiose. Revista Digital. Ano III, n. 06, p. 66-79, Jul/Dez 2014. Disponível em http://www.neliufpe.com.br/wpcontent/uploads/2015/10/o6.pdf. Acesso em 06/05/2018.

ARAÚJO, M. F. F. A; PRAXEDES, G. C. A aula passeio da Pedagogia de Célestin Freinet como possibilidade de espaço não formal de educação. Ensino Em Re-Vista, v. 20, n. 1, p. 243250, jan/jun 2013.

BRASIL (2012). Ministério da Educação, Universidade Federal do Rio de Janeiro, Museu da Geodiversidade. Acesso em o6 mar, 2018, http://www.scri.ufrj.br/index.php?option=com_content\&view $=$ article\&id $=29 \% 3$ Amuseugeodiversidade $\&$ catid $=8 \% 3$ Amuseu s\&Itemid $=19 \&$ lang $=\mathrm{br}$

CARNEIRO, C. D. R.; MIZUSAKI, A. M. P.; ALMEIDA, F. F. M. de. A determinação da idade das rochas. Terrae Didatica, 1(1), 6-35, 2005. https://doi.org/10.20396/td.v1i1.8637442

CHASSOT, A. I. Catalisando transformações na educação. $3^{\mathrm{a}}$ edição. Ijuí: Unijuí, 1993. 174p.

FALK, J; STORKSDIECK, M. Learning science from museums. História, Ciência e Saúde. Rio de Janeiro, v. 12, p. 117-198 (suplemento), 2005. 
FREINET, C. As Técnicas Freinet na Escola Moderna. Tradução: Silva Letra. 4. ed. Lis-boa: Editorial Estampa, 1975.

FREIRE, P. Pedagogia da indignação: cartas pedagógicas $e$ outros escritos. São Paulo: UNESP, 2000.

GRIFFIN, J.School-Museum Integrated Learning Experiences in Science.1998. $362 \mathrm{f}$. Thesis (Doctor of Philosophy), University of Technology, Sidney, 1998.

LEGRAND, L. Célestin Freinet. Coleção Educadores MEC. Tradução e organização: José Gabriel Perissé. Recife: Fundação Joaquim Nabuco, Editora Massangana, 2010. 15op.

MATOS, I. A. P; VITORINO, A. J. R. Educação Patrimonial: a atualidade da Pedagogia Freinet na didática das ações educativas em museus. Revista Íbero-Americana de Estudos em Educação. v. 13, n. 3, p. 1204-1224, Araraquara, 2018.

NEGRI, A. et al. Minicurso "Mina de ferro: quanto Vale? A lama de rejeitos da mineração de Mariana e os impactos de sua composição química". Laboratório de Pesquisa em Ensino de Química e Tecnologias Educativas. Faculdade de Educação da Universidade de São Paulo. São Paulo: USP, 2016a.

NEGRI, A. et al. Sequência didática "Mina de ferro: quanto Vale? A lama de rejeitos da mineração de Mariana e os impactos de sua composição química". Laboratório de Pesquisa em Ensino de Química e Tecnologias Educativas. Faculdade de Educação da Universidade de São Paulo. São Paulo: USP, 2016b.

NOGUEIRA, N; SANTOS, D. R. (Re)conhecendo patrimônios: o papel social do Museu do Samba. e-cadernos CES [Online], 30, Centro de Estudos Sociais da Universidade de Coimbra, 
2018,

p. $\quad 56-75$.

Disponível

em:

http://journals.openedition.org/eces/3782. Acesso em 19/04/2019.

OLIVEIRA, G. C. G.; MARCONSIN, N. M. A. O impacto de uma atividade não formal no cotidiano da escola. Ciências \& Cognição, v. 19, n. 3, p. 477-492, 2014.

OLIVEIRA, G. C. G.; MOREIRA, K. P. Análise de Visitas Escolares ao Museu da Geodiversidade. In: V Encontro Nacional de Ensino de Ciências da Saúde e do Ambiente - V ENECIÊNCIAS. Anais do V ENECIÊNCIAS. Niterói/RJ, 2018.

PALMIERI, L. J.; SILVA, C. S. Museus de ciência e o ensino de Química: análise sobre a produção acadêmica em periódicos e eventos. Revista Debates em Ensino de Química, v. 3, n. 2, p. 70-92, 2017.

PUGLIESE, A.; MARTINS, L. C.; LOURENÇO, M. F. Planejando uma atividade no museu: a formação de professores para a visita escolar a exposições de ciências. In: MARANDINO, M; CONTIER, D. (Org). Educação não formal e divulgação em ciência: da produção do conhecimento a ações de formação. Faculdade de Educação da USP, 2015. 106 p. il.

TARGINO, A. R. L.; GIORDAN, M. Minicurso "Elementos químicos na natureza e na sociedade: o desastre socioambiental do Rio Doce". Laboratório de Pesquisa em Ensino de Química e Tecnologias Educativas. Faculdade de Educação da Universidade de São Paulo. São Paulo: USP, 2017 a.

TARGINO, A. R. L.; GIORDAN, M. Sequência didática "Elementos químicos na natureza e na sociedade: o desastre socioambiental do Rio Doce". Laboratório de Pesquisa em Ensino de Química e Tecnologias Educativas. Faculdade de Educação da Universidade de São Paulo. São Paulo: USP, 2017b. 